\title{
Vedic Sanskrit accentuation and readjustment rules
}

\section{Readjustment in morphological theory}

This paper is a contribution to a debate which has arisen concerning the necessity of readjustment, i.e. phonological processes sensitive to morphological information, as a device for implementing allomorphic alternations, the question being whether readjustment is necessary as such, or whether these alternations can be accounted for by a combination of listed allomorphs and regular phonology. We show that, given a piece-based morphological framework such as Distributed Morphology, an accurate description of the phonology of accent in Vedic Sanskrit requires readjustment or a close analogue; listed allomorphs do not suffice to capture the observed facts. We also discuss ways in which these readjustment rules may be constrained, observing that they require a degree of derivational articulation, and that they may not be readily segregated from those phonological processes lacking morphological conditioning.

Readjustment rules are a device in Distributed Morphology (Halle and Marantz 1993) to capture morphologically conditioned alternations in the phonological form of items, and to account for phenomena such as extended exponence, whereby the presence of a morphosyntactic feature may be simultaneously signalled in two places (e.g. in a stem as well as in a suffix). The type of phenomenon which readjustment rules are invoked to account for is well exemplified by stem alternations in English irregular verbs (see e.g. Embick and Halle 2005). For instance, an example like brought, taken to be derived from initial exponents bring $+e d$, might involve two readjustment operations applying to the stem (deletion of the final consonant sequence and alteration of the vowel), and a third applying to the affix (devoicing of the consonant). As the example of ringed (i.e. encircled) shows, none of these operations can be taken to apply automatically in the relevant phonological environment. Rather the alternations depend on their morphological context.

(1) a) (n)C $\rightarrow \varnothing /\left[\mathrm{V}_{-}\right] \mathrm{T}_{\mathrm{PST}}$, where $\mathrm{V}=\sqrt{\text { think }}, \sqrt{\text { bring }}, \sqrt{\text { teach }}, \ldots$

b) $\mathrm{V} \rightarrow / \mathrm{o}: / /\left[\mathrm{V}_{-}\right] \mathrm{T}_{\mathrm{PST}}$, where $\mathrm{V}=\sqrt{\text { buy }}, \sqrt{\text { bring, }} \sqrt{\text { fight }}, \ldots$

c) $/ \mathrm{d} / \rightarrow / \mathrm{t} / / \mathrm{V}\left[\mathrm{T}_{\mathrm{PST}}-\right]$, where $\mathrm{V}=\sqrt{\text { dream }}, \sqrt{\text { bring }}, \sqrt{\text { send }}, \ldots$

As (1) shows, readjustment is conventionally formalised in terms of traditional phonological rewrite rules, but with a morphological environment. However, 
we can speak more broadly about 'readjustment' in the abstract to talk about cases where phonological statements are relativised to particular morphological environments, including not just rules of the type in (1) but also, for example, morpheme specific constraints or constraint rankings in an OT framework (e.g. Anttila 2002; Inkelas 1998; Orgun 1996; Pater 2000 among many others). While we will generally cast readjustment rules in a form similar to (1), we believe the conclusions reached here can plausibly be extended to various piece-based frameworks beyond conventional Distributed Morphology.

Readjustment has properties which seem to render it (all things being equal) an undesirable feature of a morphological theory. Left unconstrained, readjustment rules are exceptionally powerful. There is nothing to stop them from providing arbitrary lexical exceptions to phonological derivations, rendering individual phonological analyses within a given model effectively unfalsifiable. Bermúdez-Otero (2012) states this most forcefully when he says that readjustment rules "utterly destroy the empirical content of morphological and phonological hypotheses". ${ }^{1}$ What is more, in most cases where readjustment rules have been proposed, they are not easily shown to be necessary. Distributed Morphology allows the operation of Vocabulary Insertion (which yields the initial exponents of lexical items) to be conditioned by surrounding morphological environments a possibility which is required by the existence of suppletive alternations such as that between English go and went. In principle, there is no reason why the alternations accounted for by readjustment could not be dealt with by assuming an individual Vocabulary Item for each alternant. The sorts of Vocabulary Items which would be required for the example of brought are given in (2).
a) $\sqrt{\text { bring }} \leftrightarrow /$ brin/
b) $\sqrt{\text { bring }} \leftrightarrow /$ bro: $/ / \ldots \mathrm{T}_{\mathrm{PST}}$
c) $\mathrm{T}_{\mathrm{PST}} \leftrightarrow / \mathrm{d} /$
d) $\mathrm{T}_{\mathrm{PST}} \leftrightarrow / \mathrm{t} / / \mathrm{V}_{\longrightarrow}$, where $\mathrm{V}=\sqrt{\text { bring }}, \sqrt{\text { dream, }} \ldots$

Because Vocabulary Insertion may only occur once at a given node, at a very early stage of the morphophonological computation, a model making use only of

1 As Embick points out in his review of this paper, this may be something of an overstatement: while in general readjustment rules can provide exceptions to phonological generalisations in particular forms, all other phonological generalisations will be expected to hold in the forms in question, as illustrated by Halle's (1998) discussion of English accentuation - the grammar with the fewest possible exceptions will be preferred. Nonetheless, a theory with unconstrained readjustment rules still allows us to construct grammars with an arbitrary number of exceptions; if we wish to constrain the hypothesis space open to learners, this seems to be problematic. 
suppletive allomorphy does not have the undesirable effects on the falsifiability of phonological analyses which readjustment has.

Another issue with readjustment, observed in particular by Bermúdez-Otero (2012), is that it constitutes a violation of modularity. It involves the manipulation of phonological forms by operations which lie outside phonology (or, alternatively, the visibility to the phonology of features which are non-phonological in nature). Bermúdez-Otero proposes the Morph Integrity Hypothesis, given in (3).

(3) Morph Integrity Hypothesis (Bermúdez-Otero 2012: 46)

Morphological operations do not alter the syntactic specifications or phonological content of morphs.

On the other hand, conceptual arguments be made in favour of a theory incorporating readjustment (see in particular Embick and Halle 2005). Most notably, readjustment ensures that it is possible to maximise generalisations over classes of lexical items, rather than having each allomorph individually memorised in this way, readjustment allows a language learner to optimise memory usage. Both this argument and the modularity argument against readjustment seem to rely on particular hypotheses of how the language faculty functions. In our view, our aim should be to make use of empirical data to decide which (if any) of these hypotheses is correct: it does not seem to be possible to decide between them a priori. This echoes a point made by Calabrese (2015), who aims to show that metaphonic alternations in Altamurano (an Italian dialect of Apulia) are due to readjustment ('Morphophonological (MP) Rules', in his terminology) rather than listed allomorphy or regular phonology - he observes that arguments advanced on the basis of modularity against the possibility of readjustment are 'ideological' rather than empirical. Whatever conceptual objections (or advantages) there are to readjustment, conceptual arguments must fall by the wayside if the data contradicts their conclusions.

Various authors (see e.g. Embick 2010; Bobaljik 2012; Moskal 2015; Bobaljik and Harley 2017; Harley, Tubino and Haugen 2017) have suggested that incontrovertibly listed allomorphs are subject to certain locality conditions; another mechanism, for which readjustment is an obvious candidate, is then required in order to account for instances of allomorphy which obey different locality conditions. Such arguments are indeed suggestive, but not watertight - the data observed is still compatible with a model with unconstrained suppletive allomorphy and no readjustment, even if such a model does not explain the cross-linguistic patterns observed entirely satisfactorily. These arguments are also potentially subject to disproof by counterexample - they rely on the locality conditions in question being the correct ones. 
Setting metatheoretical questions aside, then, the key empirical question is whether there are any phenomena under a piece-based morphological framework such as Distributed Morphology which require the use of readjustment operations as opposed to suppletion. If there are not, then the conceptual concerns just outlined may well suffice to exclude readjustment from such a theory of morphology. This question is considered by Haugen (2016), who finds that the previous arguments for the necessity of readjustment in various languages, such as Hiaki (Harley and Tubino Blanco 2013) and Sye (Frampton 2009), do not stand up to scrutiny. What this chapter attempts to show is that the behaviour of Vedic accentuation and its interaction with ablaut require readjustment within a piecebased morphological framework such as Distributed Morphology. This entails that the Morph Integrity Hypothesis in (3) cannot be taken to be correct in such a theory, at least in its strongest form. The implications of this are discussed in Section 4.

Section 2 of this chapter sets out the relevant accentual facts for Vedic Sanskrit, and the phonological analysis of these facts. Section 3 discusses instances in Vedic where these analyses do not seem on the surface to be adequate, and shows that these anomalous cases seem to require some sort of Readjustment operation. Finally, in section 4, we discuss the implications that the necessity of readjustment, and the particular case we observe in Vedic, has for morphophonological theory, noting that the process in question requires a degree of derivational structure in the phonology, and must be interleaved with at least some phonological processes which are not morphologically conditioned.

\section{Vedic Sanskrit accentuation and ablaut}

In this section we briefly review some facts concerning the Vedic Sanskrit language, the texts from which the examples here are drawn, and the nature of its accentual and ablaut systems. Drawing primarily on Kiparsky's (2010a) account of Indo-European accent, we introduce an analysis of accentuation and its interaction with ablaut in Vedic, before turning to the problematic forms of interest in the next section.

\subsection{Vedic Sanskrit}

The language discussed here is the language of the Rgveda, a collection of hymns which is the oldest of the four Vedas, a group of Hindu scriptures dating to the first and second millennia BCE. Jamison and Brereton (2014: 5) date the 
composition of the Rgveda to the period 1400-1000 BCE. The first manuscript of the text, however, dates to the 14th century CE, more than two millennia later (Jamison and Brereton 2014:18). Despite this large interval, the text is generally considered to have been transmitted with a high degree of accuracy.

Vedic Sanskrit is an Indo-European language of the Indo-Iranian branch, and plausibly the most morphologically conservative recorded Indo-European language. Like other conservative Indo-European languages, it possesses a complex, highly fusional morphological system. It is also relatively conservative from a phonological perspective - it preserves the three-way contrast between stops (voiceless, voiced, voiced aspirated) postulated for Proto-Indo-European, as well as innovating a fourth category of stop (voiceless aspirates). It also preserves the non-nasal syllabic consonants of IE. ${ }^{2}$

Most importantly here, Vedic plausibly preserves the Indo-European accentual system more closely than any other recorded case - a fact which can be surmised, for example, from the correspondence between the position of Vedic accent and the application of Verner's law in Germanic. ${ }^{3}$

We will give a brief overview of the source of the accentual generalisations discussed here. The Vedic texts do not record accent as such. Rather, in manuscripts and critical editions, various pitch features are indicated, from which the placement of the accent can be deduced, as illustrated in (4). Specifically, a fall in pitch, known as svarita ('sounded'), and which generally follows the accented syllable, ${ }^{4}$ is indicated through a short vertical line above the syllable in question, and a low pitch before the accented syllable, known as sannatara ('more depressed'), is indicated with a horizontal line below the syllable. These can both be seen, for example, in the word पुरोहितं (puróhitam, 'foremost, priest') in (4). The high-pitched, accented syllable (known as udätta 'raised') is not marked, nor are the mid-toned (ekaśruti 'monotone') syllables following the post-accentual fall. ${ }^{5}$

2 We make use of IAST transliteration for the segments of Sanskrit. A few relevant features may benefit from being highlighted briefly. We use a macron to indicate length (so that $i$ is short and $i$ is long). The retroflex series is indicated with a dot under a coronal consonant (so that $t$ is dental but $t$ is retroflex), and syllabic consonants are indicated with a ring below (so that $r$ is a syllabic rhotic).

3 For example, the PIE *t becomes Germanic /d/ pre-tonically and / $\theta$ / elsewhere. So Old English mōdor 'mother' corresponds to Vedic mātấ, and OE brōpor 'brother' corresponds to bhrā́tā.

4 Svarita may also appear as a result of sandhi processes, e.g. when two vowels in hiatus are coalesced, if the first is accented and the second unaccented. This is known as 'independent' svarita. 5 Both ekaśruti and sannatara syllables are traditionally considered variants of a category anudātta 'not raised'. For further discussion see Monier-Williams (1857), Whitney (1879), MacDonnell (1916). 
To give an impression of how the original transcription functions, consider the first line of the Rgveda - here we give the devanägari transcription (line 1) together with a Latin transliteration (line 2). Unconventionally, we give a one-to-one transliteration of the accentual marks in the devanāgari text, transliterating the sanattara (low) here as a grave accent and the svarita (fall) as a circumflex. Line 2 also includes external sandhi effects (sound changes which occur at word boundaries). In the word breakdown in the third line, we neglect external sandhi and (as elsewhere in this paper) make use of conventional accentual transliteration, which only marks accented syllables an udattta (high pitch) syllable receives an acute accent and the independent svarita (i.e. secondary fall) is marked with a grave accent. Other syllables are left unmarked.

(4)

अग्निमींऴे
àgnimîlẹ
agní-m
agni-ACC.sG
देवमृत्विजम्

dèvamr̀̀tvijâm

devá-m

god-ACC.sG

"Agni do I invoke - the one placed to the fore, god and priest of sacrifices [. . .]" (translation from Jamison and Brereton 2014)

The sentence in (4) reflects a few properties of the Sanskrit accentual system. For instance, while there is generally a one-to-one correspondence between word and accent, this is not always the case - in particular, finite main verbs (such as ile here) are unaccented, as are nouns in the vocative case. It is also possible for a word to have multiple accents - certain compounds (particularly $d v a n d v a$ compounds, which have the interpretation of coordinated nouns) exemplify this, as discussed by Kiparsky (1982 [1984], 2010b).

The main phonological phenomenon apart from accent which will be of interest to us here is ablaut. Sanskrit syllables (like reconstructed PIE syllables) can be classified into various grades. We must posit a reduced grade (or zerograde), which contains no low vowels, a full grade (Skt. guna), which contains a short low vowel or light diphthong, and a lengthened grade (Skt. vrddhi), which contains a long low vowel or a heavy diphthong. The term 'ablaut' describes the alternation among these grades. This alternation is illustrated using forms of the root kar- 'do' below: 
(5) Ablaut grades of the root kar- $(\sqrt{d o})$

$\begin{array}{ccc}\text { Reduced Grade } & \text { kr-ta- } & \text { 'done' } \\ \text { Full Grade } & \text { kar-man- } & \text { 'action, } \text { karma' } \\ \text { Lengthened Grade } & \text { kār-ya- } & \text { '[thing] to be done' }\end{array}$

Traditionally, the reduced grade was taken to basic in most cases, and the other grades were derived from the reduced-grade form. It is, however, simpler to assume that the full grade is underlying in all cases - this allows us to fully generalise the operation (samprasārana) posited by traditional Sanskrit grammarians which transformed full-grade forms into reduced-grade forms. ${ }^{6}$

The interaction of accent and ablaut will be key to the discussion which follows - we will not be very concerned with the alternation between full and lengthened grades, but we will make extensive use of Kiparsky's (2010a) proposal that the alternation between full and reduced grades is due to the presence of an immediately following accent. This will be discussed further in the next few sections.

One topic which is of great interest, but which will not be discussed here, is the difference between the Sanskrit accentual system as it relates to nominals and as it relates to (finite) verbs. we will focus here on the nominal system, ${ }^{7}$ but an extensive discussion of the verbal system is provided in Perry (2016).

\subsection{Monosyllabic stems}

The next two subsections will review the facts of nominal accentuation in Vedic, essentially following the analysis of Kiparsky (2010a) and previous work (in particular Kiparsky and Halle 1977; Kiparsky 1982 [1984]).

Monosyllabic nominal stems in Vedic can be divided into two categories namely, those with mobile accent and those with fixed accent. In the case of the

\footnotetext{
6 The reason this rule was originally required was that full-grade low vowels could appear on either side of a root semivowel, so that we have both svap- $a$ - $t i$ ' $(\mathrm{s} / \mathrm{he})$ sleeps' and joṣ- $a-t i$ (=javș$a$-ti) '(s/he) rejoices'. To distinguish these, Sanskrit grammarians supposed that the former (but not the latter) took the full grade svap- as its basic form, and that cases where it appeared in the reduced grade (e.g. the past passive participle sup-ta-) were derived through samprasāraṇa. Here we generalise it to all roots, and rid the analysis of the operations which strengthen syllables to full grade.

7 Noting that the nominal system also subsumes the inflection of adjectives and participles.
} 
former, accent may appear (depending on the form) either on the stem or on the following gender/number/case ending. For the latter, accent always falls on the stem. This can be seen by comparing forms of the stem pad- 'foot', which is a mobile stem, and gav- 'bull', which is a fixed stem. We give a selection of inflected forms of these stems in (6).

(6)

$\begin{array}{lll}\text { Accusative Singular } & \text { gấv-am } & \text { pấd-am } \\ \text { Nominative Dual } & \text { gấv-ā } & \text { pấd-ā } \\ \text { Dative Singular } & \text { gáv-e } & \text { pad-é } \\ \text { Instrumental Plural } & \text { gó-bhis } & \text { pad-bhís }\end{array}$

As we can see from (6), each of the forms of gav- has stress on the stem. While this is also true of the accusative singular and nominative dual forms of pad-, the accent falls on the ending in the dative singular and instrumental plural. Traditionally, the forms with stem-accent are called 'strong' and the forms with accent on the endings 'weak'.

In order to capture the distinction between fixed and mobile stems in a piecebased way, Kiparsky and Halle (1977) propose that fixed stems are underlyingly accented, but that mobile stems are not. Similarly, they suppose that the endings of weak forms are underlyingly accented, but that the endings of strong forms are not. In combination with the Basic Accentual Principle, quoted in (7), these assumptions capture the different behaviour of the two types of stems (and two types of endings) in a straightforward way.

(7) Basic Accentual Principle (BAP) (as originally formulated by Kiparsky and Halle 1977: 209)

If a word has more than one [underlyingly] accented vowel, the first of these gets the word accent. If a word has no [underlyingly] accented vowel, the first vowel gets the word accent.

Clearly, whatever endings the accented stem gáv-is attached to, (7) will mean that, as the stem always possesses the leftmost underlying accent in the word, the stem is always accented on the surface, as we see in (6). When the unaccented stem pad-is attached to an accented suffix, the suffix will bear the leftmost underlying accent in the word, and will bear the surface accent. If an unaccented suffix is attached to pad-, there is no underlyingly accented syllable in the word, and the surface accent falls on the leftmost syllable (i.e. the stem), giving the patterns we see in (6). 
(8) Application of $B A P^{8}$

$\begin{array}{cc}\text { Input } & \text { Output } \\ \text { gáv }+ \text { é } & \text { gáv-e } \\ \text { gáv }+ \text { am } & \text { gấv-am } \\ \text { pad }+ \text { é } & \text { pad-é } \\ \text { pad }+ \text { am } & \text { pấd-am }\end{array}$

This applies unproblematically for the vast majority of monosyllabic noun stems.

\subsection{Polysyllabic stems}

There seems to be a similar division between fixed and mobile polysyllabic nominal stems. This can be seen by considering a selection of inflected forms of the words hotar- 'priest' and pitar- 'father'. These include the forms which will constitute one of the main points of interest in this chapter, namely the genitive plural.

(9)

\begin{tabular}{|c|c|c|}
\hline & & \\
\hline Accusative Singular & hótār-am & pitár-am \\
\hline Instrumental Plural & hótro-bhis & pitror-bhis \\
\hline Instrumental Singular & hótr-ā & pitr-ấ \\
\hline Genitive Plural & hótị̂r-ṇām & piț̣̂-ṇấm \\
\hline
\end{tabular}

In many ways, the facts in (9) look very much like those in (6). Accent remains on the stem throughout the paradigm of hotar-, but shifts to the ending in certain forms of pitar-. There are certain differences, however. Most importantly, the particular forms which display accentual shift from monosyllabic stems are different to those which show the same shift in polysyllabic stems. For example, the instrumental plural (marked with the suffix -bhis) shows accentual mobility for pad-, but not for pitar-. A second fact which requires some modification of the account so far is the difference in the placement of accent in mobile polysyllabic stems when compared with monosyllabic stems. The Basic Accentual Principle (7) predicts that when an accent falls on a mobile (i.e. underlyingly unaccented) stem such as pitar-, the accent should be placed on the leftmost syllable of the word and stem, but this is not what we see - rather we see an accent on the final syllable of the stem: pitâr-am, not * pitar-am.

8 In the output column, we give the surface form, which may have undergone processes such as vowel lengthening in addition to the BAP. 
To capture this second observation, Kiparsky (2010a) supposes that these stems are assigned a final accent at an early stage, according to a rule which he calls Oxytone. ${ }^{9}$

(10) Oxytone Rule (Kiparsky 2010a)

Accent the rightmost syllable of an inflectional stem.

Suppose that we adopt an analysis which takes these accentual generalisations to be expressed in terms of ordered rules. ${ }^{10}$ If we further suppose that the rules implementing the BAP follow Oxytone, we are then required to explain why we see any mobility at all - why does the accent assigned to pitar- by Oxytone not simply act as an underlying accent and remain fixed in all cases? The answer given by Kiparsky comes from the interaction of accentuation, ablaut and syllabification. The account given also explains the difference between monosyllabic and polysyllabic stems in terms of mobility-triggering affixes.

Kiparsky observes that a particularly regular environment for zero-grade ablaut (i.e. reduction of a syllable from its underlying full grade to its reduced grade) is the position before an underlying accent. It is this ablaut process which is responsible for the stem alternations in hotar-and pitar-. We give a semi-formal definition of the relevant operation below:

(11) $\mathrm{A} \rightarrow \emptyset /\left[{ }_{\sigma} \ldots \ldots \ldots\right]{ }^{\prime}$, where $\mathrm{A}$ is an ablauting vowel. ${ }^{11}$

9 Alternatively, we could assume these accents to be underlying, but this would miss the generalisation that no mobile stems involve anything like our hypothetical * pitar-am, and that (as Kiparsky observes) compounds of unaccented roots undergo the Oxytone rule - e.g. tri- 'three'+ vrt- 'turning' $\rightarrow$ trivrrt- 'threefold'.

10 This is the approach we will generally take throughout this paper, in part because analyses of the data in terms of ordered rules are relatively easy to formulate, but recastings of our analyses in other frameworks can be easily imagined. The conclusions we reach do not rely on a rulebased phonological framework.

11 Although most instances of $a$ undergo ablaut in this position, not all do. We consequently posit /A/ on the analogy of the abstract yer phonemes of Lightner's (1965) analysis (and many subsequent analyses) of Russian, which undergo a deletion process to which other segments are not subject, otherwise being lowered so that they are identical to other surface vowels. Alternatively, we could say that the rule here is a morphologically sensitive readjustment rule, and that /A/ should simply be taken to be /a/ in the relevant morphological contexts. Since the aim of this paper is to argue for the necessity of readjustment rules, however, to assume this would be begging the question. 
Ablaut interacts with the (re)syllabification of the relevant word. If the final consonant of a stem is followed by a vowel-initial suffix, that consonant is (re)syllabified as the onset of the following syllable.

$$
\mathrm{C}\left[{ } _ { \sigma } \rightarrow \left[{ }_{\sigma} \mathrm{C} / \_\mathrm{V}\right.\right.
$$

In the case of a reduced syllable where the final consonant is a sonorant, resyllabification of a final consonant as the onset of a final syllable bleeds a process whereby the coda of the reduced syllable is resyllabified as its nucleus.

(13)

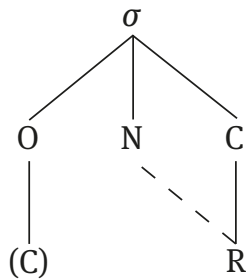

where $\mathrm{R}$ is a sonorant.

Unless there is an alternative candidate for a nucleus (e.g. in the onset of the syllable), the syllable is rendered defective, lacking a nucleus, and consequently cannot bear an accent. The relevant accent is eliminated, and the surface word accent consequently appears elsewhere. This is what Kiparsky (2010a) calls Secondary Mobility - it is this interaction, he supposes, that accounts for the mobility of pitar-. This also accounts for a regularity in the data - every ending which triggers accentual mobility in monosyllables, but not in polysyllables, is C-initial, and so would not be expected to trigger Secondary Mobility, since they do not provide the environment required for (12) to apply.

We illustrate the way this analysis proceeds in various forms of pitarin (14):

(14) Secondary Mobility in polysyllables

Acc. Sg. Ins. Sg. Ins. Pl.

pitAr-am pitAr-ấ pitAr-bhís (Input)

pitâr-am pitÁr-ấ pitâr-bhís (Oxytone, 10)

pitár-am pi'tr-ấ pi'tr-bhís (Ablaut, 11)

pitá.r-am pi't.r-ấ pi'tr-bhís (Onset, 12)

- $\quad$ - $\quad$ pitr̂́-bhís (Nucleus, 13)

- $\quad$ pit.r-ấ _ - $\quad$ (Defective Accent Deletion)

pitár-am pitr-ấ pitró-bhis (BAP, Output) 
As we can see, this derives the correct forms. In pitár-am, the ending is unaccented and does not trigger ablaut. The stem remains in its full grade and the final syllable retains its nucleus. The accent falls on that nucleus straightforwardly through the BAP. In pitr-ấ, the ending is underlyingly accented, and as such triggers ablaut in the preceding syllable. The Onset rule resyllabifies /r/, an alternative candidate for the stem-final nucleus, as the onset of the following syllable. The stem-final syllable, being left without a nucleus, may no longer bear accent, so the lexical accent is deleted. When the BAP applies, the only remaining accent is on the ending, which therefore receives the surface accent. In pitri-bhis, the ending is accented, and ablaut removes the nucleus, but the Onset rule does not apply. This means that $/ \mathrm{r} /$ may be resyllabified as the nucleus of the stem-final syllable - because the syllable is then not defective, it retains its accent. When the BAP applies, the word contains two accents, and selects the leftmost (i.e. the stem accent) as the surface accent.

There is a single cell in the nominal paradigm, however, where this analysis does not obtain the right result: namely the genitive plural, marked with the suffix -nām. This accent is C-initial, but nonetheless triggers accentual mobility,

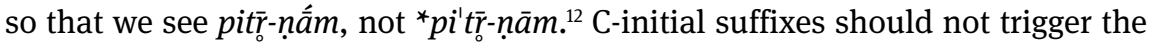
resyllabification process in (12), and consequently should not permit Secondary Mobility. The predicted (and incorrect) derivation is shown in (15), which proceeds in a manner exactly parallel to pitŕ-bhis above.

(15) Incorrect derivation of genitive plural form

$\begin{aligned} \text { pitAr-nắm } & \text { (Input) } \\ \text { pitÂr-nắm } & \text { (Oxytone) } \\ \text { pi'tr-nắm } & \text { (Ablaut) } \\ - & \text { (Onset) } \\ \text { pitr̂́-năm } & \text { (Nucleus) } \\ - & \text { (Defective Accent Deletion) } \\ \text { pit⿳亠口冋-năm } & \text { (Lengthening) } \\ \text { pit⿳亠丷厂̆-ṇām } & \text { (BAP, Retroflexion, Output) }\end{aligned}$

The anomalous behaviour of this form requires explanation, and we turn to this in the next section.

12 The retroflexion of $/ \mathrm{n} /$ here is a regular process following $/ \mathrm{r} /$ (whether syllabic or not). The lengthening we observe is morpheme specific, but could presumably be accounted for without using a readjustment rule by assuming that the suffix contains a floating mora or similar device. 


\section{Anomalous accentuation: A case for readjustment}

This section discusses two main instances where Secondary Mobility, as discussed above and by Kiparsky (2010a), does not recover the correct accentuation - these are the genitive plural, discussed briefly above, and the case forms of the present participle. We propose an analysis of these forms making use of readjustment, and show that alternative analyses fail to capture the facts.

\subsection{The genitive plural}

As mentioned at the end of the previous section, the accentuation of forms containing the genitive plural ending -nām is anomalous. Although it is an ending which is C-initial, and consequently should not trigger accentual mobility in polysyllabic stems, we actually see that it usually does trigger accentual mobility. Kiparsky makes note of this problem, and suggests that -nām is a dominant suffix: that is to say, a suffix which triggers the deletion of other accents in the word. But this cannot be the case, since there are many cases where -nām does not cause mobility - one example is the form hót $\bar{r}$-ṇa àm, where the initial syllable retains its accent, as it does with the putatively recessive desinence -bhis. More cases of this type will be discussed later in this subsection and in section 3.3.

Kiparsky does, however, provide a hint to what we believe is the correct analysis. Specifically, he observes that the -nām suffix is an innovation of the IndoIranian family (of which Sanskrit is a member) - other Indo-European languages show a vowel-initial suffix in this position. The accentual pattern we observe, then, is a result of suffix in question historically beginning with a vowel - in which case it is expected to trigger accentual mobility.

How are we to recast this historical observation in terms of a synchronic analysis? As it turns out, Sanskrit itself shows allomorphy between -nām and a vowel initial suffix - $\bar{a} m$. The alternant -nām appears after non-nasal sonorants (with certain exceptions, mostly in monosyllables), and the alternant - $\bar{a} m$ elsewhere. In the absence of readjustment rules (or some analogue thereof), we must assume (if this is really allomorphy, rather than a phonological process) that -nām and $\bar{a} m$ are in competition as exponents of genitive plural features - that is, there is no derivational relationship between the two. But a derivational relationship is precisely what we need to encode the fact that -nām acts accentually as if it is a V-intial ending. If the allomorphy is suppletive, we expect the $\mathrm{C}$-initial form to be inserted at the stage of Vocabulary Insertion (or equivalent), before phonological rules involving the suffix apply. This means we have a derivation identical to that 
we see if there was no allomorphy at all. That is, a derivation along the lines of (16), giving the incorrect output

\begin{tabular}{ll} 
(16) & \multicolumn{2}{l}{ Incorrect derivation assuming suppletive allomorphy ${ }^{13}$} \\
pitAr-\{ấm, nấm $\}$ & (Input) \\
pitÂr-\{ấm, nấm $\}$ & (Oxytone) \\
pitAr-nấm & (Allomorph Selection) \\
pi'tr-nấm & (Ablaut) \\
- & (Onset) \\
pitr̂́-nấm & (Nucleus) \\
- & (Defective Accent Deletion) \\
pit⿳亠丷厂̆-nấm & (Lengthening) \\
pit⿳亠口冋̆-nām & (BAP, Retroflexion, Output)
\end{tabular}

To obtain the correct result, we must insert - $\bar{a} m$ as the initial exponent, assign accent on that basis, and only then insert / $\mathrm{n}$ / before the suffix. Again, if we assume that readjustment rules do not exist, the most plausible analysis which permits this sort of derivational relationship would be to suppose that the $/ \mathrm{n} / \mathrm{acts}$ as a phonological hiatus-breaker, intervening between two (semi)vocalic elements. The issue here is that $/ \mathrm{n} /$ is not always inserted in this phonological environment. Take the instrumental suffix $-\bar{a}$ : phonologically speaking, there is no reason to expect this ending to act differently to the suffix - $\bar{a} m$ in creating a hiatus environment. But we never see the insertion of $/ \mathrm{n} /$ before this suffix - we see pitr- $\bar{a}$, not * pitr-nấ. The insertion of $/ \mathrm{n} /$ seems to be sensitive to the morphological identity of the ending. One approach which has been taken to deal with morphologically specific insertion rules of this sort has been to assume what Zimmermann (2016) calls a 'mono-representational' analysis of allomorphy, where two allomorphs are derived from a single underlying representation. Typically this involves material (segmental or otherwise) which is present in the underlying representation without being attached to a node necessary for its realisation, leading to its being unrealised if not later associated by a phonological process. ${ }^{14}$ In the present case, rather than two allomorphs - $\bar{a} m$ and $-n \bar{a} m$, we would posit a single underlying form for both, with a floating $n$ which remains unrealised in most instances. The

13 Here assuming allomorph selection as late as possible in the derivation - it can be supposed to follow Oxytone, which applies only to the stem and is not sensitive to properties of the affix, but must precede Ablaut, which crucially relies on accentual properties of the affix.

14 For recent analyses along these lines see in particular Trommer (2011), Bye and Svenonius (2012), who focus on affixation of floating subsegmental elements, and Scheer (2016), who focuses on floating segments. 
representation of the genitive plural suffix $-(n) \bar{a} m$, then, would be something like the following (abstracting away from subsyllabic structure):

(17)

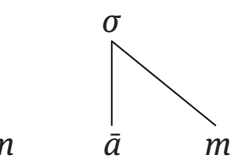

This too yields incorrect results, however. We would expect the floating $n$ segment to be syllabified as the onset of the final, suffixal syllable in preference to the more distant $r$, meaning that, again, we would not expect accent shift - the derivation would proceed along more or less the same lines as (15) and (16), as shown in (18).

(18) Incorrect derivation using monorepresentational analysis ${ }^{15}$

\begin{tabular}{|c|c|}
\hline pitAr-〈n〉ắm & (Input) \\
\hline pitÂr-〈n〉ấm & (Oxytone) \\
\hline pi'tr-〈n〉ấm & (Ablaut) \\
\hline pi'tr-nắm & (Onset) \\
\hline pitr̂́-nấm & (Nucleus) \\
\hline & (Defective Accent Deletion) \\
\hline & (Lengthening) \\
\hline$i t \overline{\underline{n}}$ & (BAP, Retroflexion, Output) \\
\hline
\end{tabular}

To obtain the correct results, it seems that we must assume $n$ to be entirely absent from the representation when the Onset resyllabification rule applies, before being inserted by a morphologically specific process.

To summarise, the relationship between - $\bar{a} m$ and -nām must be derivational in nature (i.e. not suppletive), and must be conditioned by morphological properties. This kind of relationship is exactly what readjustment rules encode. That is to say, the behaviour of the Sanskrit genitive plural seems to require readjustment. The proposed rule is given in (19):

$$
\varnothing \rightarrow / \mathrm{n} / /\left[\begin{array}{l}
+ \text { son } \\
+ \text { cont }
\end{array}\right]-\mathrm{K}_{[+ \text {gen },+\mathrm{pl}]}
$$

15 Here the floating segment is enclosed by triangular brackets \langle\rangle . 
This rule, it must be supposed, applies after the operations resulting in Secondary Mobility, but before a late resyllabification rule which reassociates a coda sonorant with a preceding nucleus. The derivation of pitr̄-nấm is given in (20), with readjustment rule (19) in bold.

(20) Successful derivation using Readjustment Rule

\begin{tabular}{|c|c|}
\hline pitAr-ấm & (Input) \\
\hline pitÂr-ấm & (Oxytone) \\
\hline pi'tr-ấm & (Ablaut) \\
\hline pi't.r-ấm & (Onset) \\
\hline- & (Nucleus) \\
\hline pit.r-ấm & (Defective Accent Deletion) \\
\hline pit.r-nấm & (n-Insertion, 19) \\
\hline pitron-nắm & (Late Resyllabification) \\
\hline pitợ-nấm & (Lengthening) \\
\hline pitr̄̄-nâ̆m & (BAP, Retroflexion, Output) \\
\hline
\end{tabular}

This derivation behaves in exactly the same way as pitr-áa up to the deletion of accents in defective syllables. After the stem-final accent is deleted in this way, the $\mathrm{n}$-insertion readjustment rule applies, followed by the 'late resyllabification' operation (or operations) above, which associate the inserted $/ \mathrm{n} /$ with the onset of the word-final syllable and the stem-final /r/ with the final nucleus of the stem.

What this analysis predicts is that in all polysyllabic stems where we have Secondary Mobility as a result of Ablaut and resyllabification, -nām should attract accent. In other polysyllabic stems, where Secondary Mobility does not apply, we predict that accent before -nām should remain stable. This distinguishes the approach here from Kiparsky's identification of -nām as a 'dominant' affix (discussed further at the end of this section), which predicts that -nām should trigger accent shift in all stems.

Other ablauting stems which take -nām in their genitive plural do indeed seem to show mobility. For instance, we see kavī-nấm 'poet-GEN.PL', with mobile accent. And indeed this is an ablauting stem of the sort we expect to undergo accentual mobility (although the ablaut pattern is somewhat more complex than that obeyed by r-stems), as we can see from the nominative plural of the word for poet, which displays full grade and retains its accent: kaváy-as.

Now consider stems like nadi- 'river'. These have the genitive plural ending -nām, but we do not see accentual mobility: we have nadí-nām, not *nadī-nấm. 
And indeed, as predicted, we do not see ablaut alternation in this stem: the nominative plural is nadíy-as (> nadyàs), not * nadáyas. ${ }^{16}$

$\begin{array}{ll}\text { (21) nadī-ấm } & \text { (Input) } \\ \text { nadí-ấm } & \text { (Oxytone) } \\ - & \text { (Ablaut) } \\ \text { nadí-yấm } & \text { (Onset) } \\ \text { nadí-nấm } & \text { (n-insertion) } \\ \text { nadí-nām } & \text { (BAP, Output) }\end{array}$

The final syllable of the stem nadi- remains in its reduced grade (albeit with lengthening) throughout its paradigm, presumably because the underlying form of the stem lacks /a/. Another set of stems of interest will be those which show full grade throughout their paradigm. One example of such a class is the set of thematic stems - those which form their stem by combining a root (or sometimes a derived form) with a theme vowel $-a-$. This $/ a$ / is non-ablauting, and so we expect these forms to always retain their accent when combined with the genitive plural suffix -nām. This is indeed what we see - for instance, the genitive plural of the thematic stem deva- is devấ-nām, not * $\operatorname{deva\overline {a}-nấm}$.

$\begin{array}{ll}\text { (22) deva-ấm } & \text { (Input) } \\ \text { devá-ấm } & \text { (Oxytone) } \\ - & \text { (Ablaut) } \\ - & \text { (Onset) } \\ \text { devá-nắm } & \text { (n-insertion) } \\ \text { devấ-năm } & \text { (Lengthening) } \\ \text { devấ-nām } & \text { (BAP, Output) }\end{array}$

In conclusion, the distribution of accentual mobility triggered by the Genitive Plural marker -nām is exactly what we would expect if the marker in question triggered secondary mobility in exactly the same way as V-initial markers, and not

\footnotetext{
16 The surface form of the nominative plural here (nadyàs) is syncopated. That this is a relatively late process is indicated by the independent svarita which appears here rather than the secondary mobility we see with ablauting stems. This suggests that the syncope follows pitch-accent assignment - independent svarita elsewhere tends to result from post-lexical sandhi processes. Not all stems in - $\bar{\imath}$ behave in exactly the way that nadi- does. So-called devi stems, while they do not show accent shift in the genitive plural, do undergo relatively early syncope and consequent secondary accent shift. The point, however, is that this shift does not result from ablaut - i.e. it is possible to order the relevant process after $n$-insertion.
} 
what we would expect if we took it to be accentually 'dominant'. This is straightforwardly captured by positing a readjustment rule which inserts an $n$ before the initial exponent - $\bar{a} m$, a rule which applies after secondary mobility has taken place. In what follows, we will consider other cases where a similar readjustment rule resolves problems in the distribution of Vedic accent.

\subsection{Participles}

If formed from an unaccented verb stem, the Vedic present participle ${ }^{17}$ shows mobility identical to that of ablauting nouns ending in a sonorant, discussed in the previous section. What makes this unexpected is a) that the present participle appears to underlyingly end in a consonant cluster, not a single consonant - so that resyllabification would not be expected to render a syllable defective and b) that the present participle, even in its ablauting forms, always displays a full vowel in the final syllable of its stem.

The accentuation of the present participial forms (the participial ending followed by case/number markers), as they appear when attached to an unaccented verbal base, is illustrated in the table below:

(23) Declension and accentuation of present participle (with unaccented base)

\begin{tabular}{|c|c|c|c|}
\hline & Singular & Dual & Plural \\
\hline Nominative & -án & \multirow{2}{*}{-ánt-ā } & -ánt-as \\
\hline Accusative & -ánt-am & & -at-ás \\
\hline Instrumental & -at-ấ & \multirow{3}{*}{-ád-bhyām } & -ád-bhis \\
\hline Dative & -at-é & & -ád-bhya \\
\hline Ablative & \multirow{2}{*}{-at-ás } & & \\
\hline Genitive & & \multirow{2}{*}{-at-ós } & -at-ấm \\
\hline Locative & -at-í & & -át-su \\
\hline
\end{tabular}

As will be observed, the accent of the participle shifts to the ending if and only if that ending is both accented ${ }^{18}$ and V-initial. This is exactly the pattern we

17 Or more precisely, non-perfect participial forms, including so-called aorist participles as well as present participles proper. These inflect with the same suffix, but a different stem; the difference between present and aorist participles is not relevant here, and we will use the term 'present participle' loosely to refer to both.

18 Cases with unaccented endings are the nominative and accusative singular and dual, and the Nominative plural. 
expect from the application of Secondary Mobility, as outlined in the previous section. But the Secondary Mobility effect cannot be straightforwardly derived here, as it can for a sonorant-final stem. Recall that Secondary Mobility was a consequence of resyllabification of a final consonant creating a defective syllable in an ablauted form. Here, ablauted forms of the stem-final syllable preceding a V-initial suffix and those preceding C-initial suffixes do not differ. In both cases, the syllable contains a filled nucleus - consider locative plural -át-su and locative singular - at-í. Even if we resyllabify the stem-final consonant / $t$ / as the onset of the following syllable, $/ \mathrm{n} /$ is still present in the stem-final syllable, and may be resyllabified as the nucleus when ablaut applies. ${ }^{19}$ This being the case, we should expect fixed accent on the participial ending.

We can observe that the nominative singular form of the participle lacks the final / $t$ / of the participial ending. This is not surprising, since Sanskrit forbids word-final consonant clusters in general. It does, however, give us a hint to the solution to our problem. Suppose that the nominative singular, being the most frequent form, has also been reanalysed as the underlying form - i.e. as the initially inserted exponent of the present participle. As was the case with the genitive plural ending, we require a derivational relationship between participial endings -an- and -ant-: competition between these exponents at the point of insertion simply fails to give us the relevant accentual facts. Suppose, then that a readjustment rule (shown in (24)) inserts / $t$ / after the participial ending following Secondary Mobility, but before the late resyllabification process which we posited for the genitive plural, above.

$$
\mathrm{n} \rightarrow \mathrm{nt} /\left[\mathrm{Wd}\left[\mathrm{Ptcp}_{[- \text {perf }]} \ldots .\right] \mathrm{X}\right] \text {, where } \mathrm{X} \text { is any phonological material. }{ }^{20}
$$

This must be a readjustment rule rather than a phonological rule as it does not apply in all morphological environments - for example, there are plentiful examples of n-stemmed nouns like naman- 'name' or rājan- 'king', which never display the / $t$ / we see here. The rule in (24), applying after Secondary Mobility, produces exactly the forms we see in (3.2). Derivations of some relevant participial forms of the verb root śuc- 'to shine' are shown below:

19 This syllabic /n/ is realised on the surface as $a$. That this represents a resyllabification of $/ \mathrm{n} /$ is indicated by the fact that surface $n$ alternates with $a$ in exactly the same contexts as surface $r$ alternates with $r$. Alternative analyses of alternations such as that observed here between -ant and - at can be imagined, but this makes no substantive difference to the argument here: whatever the analysis adopted, the presence of the final / $t$ / would be expected to block accent shift. 20 A slightly broader environment may be necessary here - exactly the same facts we observe in participles hold for the proprietive adjectival endings - an $(t)$, - $\operatorname{man}(t)$ and -van $(t)$. The only difference in these cases is that the nominative singular form shows lengthening (e.g. mahān 'great', *mahan). 
(25) Participial forms and Secondary Mobility

$\begin{array}{llll}\text { Nom. Pl. } & \text { Gen.Sg. } & \text { Ins. Pl. } & \\ \text { śuc-An-as } & \text { śuc-An-ás } & \text { śuc-An-bhis } & \text { (Input) } \\ \text { śuc-Ân-as } & \text { śuc-Án-ás } & \text { śuc-Án-bhís } & \text { (Oxytone) } \\ \text { śuc-án-as } & \text { śu'c-n-ás } & \text { śu'c-n-bhís } & \text { (Ablaut) } \\ \text { śuc-á.n-as } & \text { śu'c-.n-ás } & \text { śu'c-n-.bhís } & \text { (Onset) } \\ \text { śuc-án-as } & - & \text { śuc-ñ-bhís } & \text { (Nucleus) } \\ - & \text { śuc-n-ás } & - & \text { (Defective Accent Deletion) } \\ \text { śuc-ánt-as } & \text { śuc-nt-ás } & \text { śuc-ñt-bhís } & \text { (t-insertion, 24) } \\ - & \text { śuc-ñt-ás } & - & \text { (Late Resyllabification) } \\ - & \text { suc-at-ás } & \text { suc-át-bhís } & \text { (n-vocalisation) } \\ - & - & \text { śuc-ád-bhís } & \text { (Voice Assimilation) } \\ \text { śuc-ánt-as } & \text { śuc-at-ás } & \text { śuc-ád-bhis } & \text { (BAP, Output) }\end{array}$

Again, we see that a readjustment rule (in bold here), applying after Secondary Mobility, gives us the right result.

It may be instructive to compare this case to the perfect participle, which does not show accentual mobility. As with the present participle, the nominative singular form is sonorant-final. We might expect that it, too, would serve as a trigger for reanalysis, and that the perfect participle would undergo similar Secondary Mobility, but this is not what we see - instead we see fixed accent on the participial ending. The relevant forms are given in (26). ${ }^{21}$

(26) Declension and acentuation of perfect participle

\begin{tabular}{|c|c|c|c|}
\hline & Singular & Dual & Plural \\
\hline Nominative & -vấn & \multirow{2}{*}{-vấṃs-ā } & -vấms-as \\
\hline Accusative & -vấṃs-am & & -úṣ-as \\
\hline Instrumental & -úṣ-ā & \multirow{3}{*}{ (-vád-bhyām) } & -vád-bhis \\
\hline Dative & -úș-e & & \\
\hline Ablative & \multirow{2}{*}{-úṣ-as } & & (-vád-bhya \\
\hline Genitive & & \multirow{2}{*}{ (-úṣ-os) } & -úṣ-ām \\
\hline Locative & (-úṣ-i) & & (-vát-su) \\
\hline
\end{tabular}

It might be reasonable to attribute the failure of reanalysis in this case to the more complex allomorphy of the perfect participle. Abstracting away from superficial

21 The forms in parentheses here are unattested in the Rgveda, but rather are inferred from the corresponding Classical Sanskrit forms. 
differences caused by processes like voicing assimilation, the present participle has three forms: -an, -ant- and -at-. Deriving the last two forms from the first is a relatively simple matter of applying the independently motivated process of ablaut, in addition to the t-insertion process of (24). The perfect participle, on the other hand, has four forms which differ non-trivially: -vān, -vāṃs-, -vat- and -uṣ-. Deriving a form such as -uṣ- from -vān is a much less transparent process than deriving - at- from - an, and so reanalysis of the Nom. Sg. as underlying here may be disfavoured.

To conclude, we can see that the accentuation of the genitive plural is not the only accentual phenomenon in Vedic which motivates readjustment, and that the paradigm of the Present Participle provides further support for the necessity of readjustment. We now turn to discuss possible analyses of these phenomena which do not require readjustment, showing how these analyses are (in various ways) inadequate to account for the data we see.

\subsection{Alternatives}

As was mentioned in section 3.1, Kiparsky (2010a) proposes that the genitive plural -nām is a dominant suffix. We dismissed this in rather short order, and it may be worth examining the proposal in a little more detail, to show why it cannot account for the phenomena we observe.

The dominant suffixes are a set of affixes in Sanskrit which produce forms other than those which would be expected from the Basic Accentual Principle (7) alone - they apparently trigger the deletion of lexical accents. Kiparsky (1982 [1984]) divides these into three categories - dominant accented suffixes, which remove lexical accents in preceding material, but are accented themselves (e.g. the past passive participle suffix -ta: kâr 'do' $+t a \rightarrow k r$-tá- ), dominant preaccenting suffixes, which cause the accent to surface on the preceding syllable (e.g. the nominaliser -tā: púruṣa $+t \bar{a} \rightarrow$ puruṣá-tā), and dominant unaccented suffixes, which remove lexical accents, but are not themselves accented, so that the BAP assigns initial accent (e.g. the comparative suffix -iyams: prati-cyáv- 'moving towards' $\rightarrow$ práti-cyav-iyams- 'moving more [ardently] towards'). Affixes which do not trigger accent deletion are called recessive affixes.

Because 'dominance' is a morphologically specific property which triggers accentual effects, it might reasonably be supposed to be a result of readjustment. This is not necessarily the case, however: Halle and Vergnaud (1987), for example, building on Kiparsky (1982 [1984]), propose an analysis whereby accentual dominance is a consequence of phonological cyclicity. In their analysis dominant suffixes are cyclic (unlike recessive suffixes), and the accentual derivation is erased 
each cycle. While there is reason to believe that this analysis does not suffice, at least in a Distributed Morphology framework (see Perry 2016), we can assume for the time being that some mechanism other than readjustment is responsible for accentual dominance.

Is it possible, then, to treat the genitive plural marker -nām as an dominant suffix? We can show straight away that it is not, by observing that it may attach to fixed-accent stems without removing their accent, so that we see hótr-nām 'of the priests', never *hotr-nấm. But what of a more 'locally' dominant affix? I.e. one which deaccents only the syllable immediately preceding it? One can imagine various ways of achieving this without explicitly invoking readjustment - for example, perhaps the suffix is associated with some sort of floating low tone, which triggers deletion of a preceding high.

This solution, too, is inadequate, as we can see from forms like devấ-nām 'of the gods' and nadí-nām 'of the rivers' ( ${ }^{\star} \operatorname{dev} \bar{a}-n a \bar{m}$, * nadī-nấm). Clearly, not all instances of -nām trigger deletion of the preceding accent. As a last-ditch attempt, we might say that there are different allomorphs of -nām - some which are 'locally dominant' in the relevant sense, and some which are not, and that these allomorphs are selected by different stems.

This solution, however, is undesirable for various reasons - besides the fact that it must posit two separate allomorphs (which must also be suppletive, forming entirely different vocabulary entries, given that we are not assuming the existence of readjustment rules) that are identical on the surface, ${ }^{22}$ we then entirely lose the generalisation that we observe accent shift after ablauting syllables, but not elsewhere: the differing behaviour of nadí -nām 'of the rivers' and kavī-nấm 'of the poets' must simply be stipulated.

Finally, this analysis is of no help at all when we turn to the accentual behaviour of participles. While readjustment allows us to account for the anomalous accentuation of participles along much the same lines as the accentuation of the genitive plural (albeit with a different rule), the idea of local dominance cannot easily explain the behaviour of participles - we would have to assume that all V-initial accented suffixes were locally dominant in the relevant sense when attached to a participle. That is to say, all vowel-initial suffixes would have two suppletive allomorphs: one which triggers deletion of a preceding accent, and one which does not. Furthermore, each of the former set of allomorphs must

22 This is, in principle, permissible even in a framework where we assume a constraint along the lines of Embick's (2003) Avoid Accidental Homophony. This hypothetical analysis would take these forms not to be precisely homophonous, but with a floating feature which distinguishes them. The question of how the relevant representations are acquired given their surface identity remains, however. 
occur only in one environment - after the participles in question. ${ }^{23}$ While this system is in principle permitted by a framework such as Distributed Morphology, it provides us with no explanation whatsoever of the phonological regularities we see in the data.

Perhaps, though, the explanation for configurations like these lies outside the synchronic linguistic system of these languages. Although the proposed synchronic system, making use of allomorphically conditioned locally dominant affixes, does not give us an explanation for any of the observed regularities in the system, it may be that an amphichronic approach to this problem (in the sense of Kiparsky 2006, Bermúdez-Otero 2013) is necessary - that is to say, the explanation for the present system lies in its historical development. This could plausibly be argued for the case of the genitive plural, where the insertion of $/ \mathrm{n} /$ before the genitive affix is an innovation. However, we run into problems when we consider participles. Here the forms with / $t$ / are conservative - the loss of / $t$ / in the nominative singular is a result of phonological simplification of a word-final cluster. The participial forms with accent shift, in other words, have never had a sonorant at the end of their stem. That is, there has never been a historical configuration which we would expect to yield Secondary Mobility in the phonology - meaning that an amphichronic approach does not provide any more explanation than the synchronic system just discussed.

\section{Conclusion: Restraining readjustment}

We have argued that readjustment rules, or some close analogue, must be responsible for phenomena which condition the distribution of Vedic accent, so long as we analyse it in a piece-based, compositional way. It seems likely that Vedic is not the only case where readjustment is required in this way - readjustment is required by any process where we have two phonologically similar allomorphs $\mathrm{X}$ and $\mathrm{Y}$, with a phonological process expected to be triggered by allomorph $\mathrm{X}$ and not allomorph $\mathrm{Y}$, but where the process in question does in fact apply in the environment of both allomorphs. Any case where we have a process triggered by vowel-initial syllables but not by consonant-initial syllables, for instance, but where this process emerges before a consonant-initial allomorph of an otherwise vowel-initial morpheme, will require a readjustment-based analysis. As Embick

23 Even the genitive plural, for which we have independently proposed this allomorphy, must have a unique allomorph following the relevant participle. This is because the form of the allomorph in question is - $\bar{a} m$, while the form which is 'locally dominant' in other cases is -nām. 
observes in his review of this chapter, morphologically specific operations inserting consonants in hiatus position are not particularly rare in the languages of the world. ${ }^{24}$ This may well be a productive domain in which to find further examples of the sort of phenomenon discussed here.

The question is, where do we go from here? The conceptual objections to readjustment - that it makes it difficult to formulate testable phonological analyses, and that it constitutes a violation of strict modularity, remain. What, then, are we to conclude from their apparent necessity, in spite of these arguments?

One obvious tack starts by observing that the conclusion that readjustment rules are necessary is only forced upon us if we insist on a piece-based analysis of Vedic morphology and accent. Perhaps what we should conclude from the result here, then, is that a piece-based analysis is untenable, and that we should instead pursue a paradigmatic approach to accent (and ablaut), one in which we simply state, for instance, that it is a property of the genitive plural cell that accent is borne on the ending in the relevant set of nouns, or that the set of stems ending in -nt displays accent on the ending in V-initial 'weak' forms. ${ }^{25}$ It is not within the scope of this chapter to discuss the merits of a paradigmatic approach as opposed to the piece-based approach we have been assuming, but it is worth noting that, in any case, we are forced to assume that phonological properties (including, but not limited to, accent placement) can be conditioned by morphological considerations - paradigmatic approaches, then, do not seem to represent an improvement as far as modularity is concerned.

If we do not abandon the piece-based approach, we must accept that some readjustment is necessary. But that is not to say, of course, that we must allow unconstrained readjustment rules to apply throughout the phonological derivation. One useful feature of cases like the Vedic accentual system, where readjustment can be shown to be a necessity, is that they allow us to test which restrictions on the operations in question may hold. There are two ways in which we can constrain readjustment rules - by constraining their form, and by constraining their interactions with other components of the phonological derivation. We will briefly discuss some possible constraints of the latter type.

One constraint on readjustment that the Vedic data is compatible with is proposed by Embick (2010). He supposes that readjustment is cyclic, and that

24 e.g. in Turkish the 3rd person possessive marker and accusative marker both have a V-initial allomorph /i/ which appears after consonants, but after vowels these markers surface as /si/ and /ji/, respectively.

25 That is, those which we analyse as having underlyingly accented endings. 
the morphological trigger must share a cycle with a (morphologically specified) target. ${ }^{26}$

(27) Readjustment Activity Hypothesis (Embick 2010: 101)

A readjustment rule triggered by a morpheme $\mathrm{X}$ can effect a Root- or morpheme-specific change only when $\mathrm{X}$ and the Root/functional head are in the same PF cycle.

If we identify the PF cycle with the syntactic Spellout cycle or phase domain (Chomsky 2000), or indeed a slightly larger domain (following Embick, who takes a phonological spellout cycle to constitute not only a syntactic phase domain, but also all heads lying between that domain and the next phase head), this condition is readily satisfied: the case marker lies within the maximal nominal projection, which can plausibly be taken to constitute a phase domain (as assumed by e.g. Svenonius 2004; Bošković 2005, 2013 among others). ${ }^{27}$

On the other hand, one constrained model of readjustment with which the data here are not straightforwardly compatible is a monostratal OT model which implements readjustment using morphologically indexed constraints (e.g. the model adopted by Pater 2000). Recall that in order to capture the accentual facts, we require a derivational relationship between the initially inserted allomorph - $\bar{m} m$ and the derived allomorph - nām. And not only this: $n$-insertion counterbleeds accent shift, which means that the insertion of the initial exponent must apply at a different stage to readjustment. This, of course, presents the same issues to a monostratal OT model as any other instance of counterbleeding, and so readjustment cannot apply as part of such a computation.

26 Embick in his review of this chapter suggests that this could be tested by investigating category-changing morphology; unfortunately this is not possible using the Vedic phenomona under discussion. One case of category changing morphology which does participate in the phenomenon here is the participial marker, which attaches to a verb stem and creates a nominal form. But since the outermost categorial head will generally be taken to share a cyclic domain with a following case marker (since it lies outside the phase domain that it heads - see next paragraph), its behaviour is not informative. The ideal test-case might involve zero-derivation from an already-categorised item, where the behaviour of the inner categoriser with respect to readjustment would test this hypothesis, but this case does not seem to arise straightforwardly in Vedic. 27 This is one reason to reject Halle and Vergnaud's (1987) analysis of accentual dominance as a consequence of 'cyclic' affixation: case markers do not trigger deletion as dominant affixes do, but are plausibly taken to share a phonological cycle with the noun to which they are attached. Halle and Vergnaud assume that the cyclic/non-cyclic distinction is entirely diacritic, but if we assume any non-arbitrary correlation between the syntactic and phonological cycle, their account cannot be retained. 
Apart from cyclicity, what possible constraints on readjustment are permitted in a derivational model? One broad notion that we might expect to be adhered to is that readjustment rules are 'early', in that they precede straightforwardly phonological rules, even where those rules take place in the same cycle. This, of course, recalls the restriction of morpheme-specific phonological rules to the lexicon in Lexical Phonology models (Mohanan 1982). And indeed we see that the readjustment rules here are preceded and followed by other morpheme-specific processes, such as ablaut, or the lengthening triggered by the genitive plural, making it plausible that there is a readjustment 'block' which precedes other phonological operations. Issues remain, however - interleaved within this block are rules which are not obviously conditioned by morphological structure. The most obvious of these are the rules which resyllabify items, whether as onsets or as nuclei, but also the Oxytone rule which seems to apply without exception. ${ }^{28}$ This would not be an issue in a Lexical Phonology framework, where we can analyse morphology-sensitive readjustment operations and the interleaved phonological rules alike as lexical phonological rules, albeit with morphological indexing in the former. In any framework such as Distributed Morphology which dispenses with a generative lexicon, however, these considerations take on more importance. In order to retain the notion of an readjustment 'block', we could distinguish between phonological rules, and readjustment rules which happen not to have any morphological conditioning. Unless we have a principled way to distinguish the former from the latter, however, this is no different from assuming that phonological rules may be freely interleaved with readjustment operations.

One tempting way retain some notion of a readjustment block would distinguish between structure-building and structure-changing operations. Syllabification operations may be taken to exemplify the former, and Oxytone might also plausibly be taken to constitute a metrical structure-building operation. Then we could allow structure-building to be interleaved with readjustment rules, but not structure-changing operations. ${ }^{29}$ This, in combination with the cyclicity condition

28 A prima facie exception can be found in verbs with athematic presents. These display accentual mobility even with C-initial suffixes, suggesting that there is no Oxytone accent present. However, the ablaut patterns here indicate the presence of Oxytone accent, suggesting that it is indeed inserted early, but removed by a later (morphologically specific) process. This seems to be confirmed by the behaviour of reduplicating verbs, where the distinction between C-initial suffixes and V-initial suffixes is visible in the direction of mobility (so that from the root bhar we see $1 \mathrm{pl} b i \sim b h r$-más but $3 \mathrm{pl} b i \sim b h r-a t i)$. This does not seem readily explicable without some sort of secondary mobility triggered by the V-initial suffix, which would be unmotivated unless Oxytone accent was assigned.

29 Cf. the distinction between structure-building and structure-changing assumed by Kiparsky (1982), who assumes that structure-building is not subject to the Strict Cyclicity Condition (and 
above, would at least present some constraint on the phenomena for which readjustment is to be posited.

These and other constraints on readjustment must be considered if we are to retain a theory of (morpho)phonology which permits us to develop falsifiable analyses of phonology. The essential point demonstrated by the case of Vedic accentuation, however, is that some kind of Readjustment, however it is to be constrained, is forced upon us by piece-based analyses of morphophonological processes.

Acknowledgments: We thought it appropriate to contribute a piece combining empirical and theoretical work spanning Sanskrit phonology, morphology, and syntax, given the second author's fond memories of Andrea's inspirational ability to navigate these complex waters in his own research and teaching. It was in fact Andrea who first made the second author aware of the theoretical importance and potential of the Sanskrit stress system when he was Andrea's graduate student in the early 1990s. This paper is a development of a conference paper entitled "Allomorphy, Morphophonology and Opacity in the Accentuation of the Vedic Noun", given by the first author at the second Edinburgh Symposium on Historical Phonology (ESHP). Thanks are due to members of the ESHP2 audience (in particular Ricardo Bermúdez-Otero) and members of the Cambridge Experimental Phonetics and Phonology research cluster for their helpful comments and questions. Thanks also to an anonymous reviewer and the onymous David Embick for their suggestions. All errors are, of course, our own.

\section{References}

Anttila, Arto. 2002. Morphologically conditioned phonological alternations. Natural Language and Linguistic Theory 20(1). 1-42.

Bermudez-Otero, Ricardo. 2012. The architecture of grammar and the division of labour in exponence. In Jochen Trommer (ed.), The morphology and phonology of exponence, Oxford: Oxford University Press.

consequently does not display derived environment effects), while structure-changing rules are subject to the SCC and may not apply in non-derived environments. This allows underived stems to be metrified in English, for example. Halle and Mohanan (1985) suppose that the BAP in Vedic is a structure-changing operation, since some metrical information seems to be specified underlyingly in the language. If we follow them in assuming that there is a distinction between accent (concrete tonal specifications) and stress (abstract prominence), however, we can suppose that only the former is encoded in the UR, allowing at least some metrical processes to be treated as structure-building. 
Bermudez-Otero, Ricardo. 2013. Amphichronic explanation and the life cycle of phono-logical processes. In Patrick Honeybone \& Joseph Salmons (eds.), The Oxford handbook of historical phonology, Oxford: Oxford University Press.

Bobaljik, Jonathan. 2012. Universals in comparative morphology. Cambridge, MA: MIT Press.

Bobaljik, Jonathan \& Heidi Harley. 2017. Suppletion is local: Evidence from Hiaki. In Heather Newell, Máire Noonan, Glyne Piggott \& Lisa Travis (eds.), The structure of words at the interfaces, Oxford: Oxford University Press.

Boškovic, Željko. 2005. On the locality of left branch extraction and the structure of NP. Studia Linguistica 59(1). 1-45.

Boškovic, Željko. 2012. Phases beyond clauses. In Lilla Schürcks, Anastasia Giannakidou \& Urtzi Etxeberria (eds.), The nominal structure in Slavic and beyond, Berlin: De Gruyter Mouton.

Bye, Patrik \& Peter Svenonius. 2012. Exponence, phonology and non-concatenative morphology. In Jochen Trommer (ed.), The morphology and phonology of exponence, Oxford: Oxford University Press.

Calabrese, Andrea. 2015. On the morphophonology of metaphonic alternations in altamurano. In Fransesc Torres-Tamarit, Kathrin Linke \& Marc van Oostendorp (eds.), Approaches to metaphony in the languages of Italy, Berlin: De Gruyter Mouton.

Chomsky, Noam. 2000. Minimalist inquiries: The framework. In Roger Martin, David Michaels \& Juan Uriagereka (eds.), Step by step, Cambridge, MA: MIT Press.

Embick, David. 2003. Locality, listedness and morphological identity. Studia Linguistica 57(3). 143-169.

Embick, David. 2010. Localism versus Globalism in Morphology and Phonology. Cambridge, MA: MIT Press

Embick, David \& Morris Halle. 2005. On the status of stems in morphological theory. In Twan Geerts, Ivo van Ginneken \& Haike Jacobs (eds.), Romance languages and linguistic theory 2003, Amsterdam: John Benjamins. 2003, Amsterdam: John Benjamins.

Frampton, John. 2009. Distributed reduplication. Cambridge, MA: MIT Press.

Halle, Morris. 1998. The stress of English words 1968-1998. Linguistic Inquiry 29(4). 539-568.

Halle, Morris \& Alec Marantz. 1993. Distributed morphology and the pieces of inflection. In Kenneth L. Hale \& Samuel Jay Keyser (eds.), The view from building 20, Cambridge, MA: MIT Press.

Halle, Morris \& K. P. Mohanan. 1985. Segmental phonology of modern English. Linguistic Inquiry 16(1). 57-116.

Halle, Morris \& Jean-Roger Vergnaud. 1987. An essay on stress. Cambridge, MA: MIT Press. Harley, Heidi \& Mercedes Tubino Blanco. 2013. Cycles, vocabulary items and stem forms in Hiaki. In Alec Marantz \& Ora Matushansky (eds.), Distributed morphology today, Cambridge, MA: MIT Press.

Harley, Heidi, Mercedes Tubino \& Jason D. Haugen. 2017. Locality conditions on suppletive verbs in Hiaki. In Vera Gribanova \& Stephanie S. Shih (eds.), The morphosyntax-phonology connection, Oxford: Oxford University Press.

Haugen, Jason D. 2016. Readjustment: Rejected? In Daniel Siddiqi \& Heidi Harley (eds.), Morphological metatheory, Cambridge, MA: MIT Press.

Inkelas, Sharon. 1998. Segmental phonology of modern English. Yearbook of Morphology 1997. 121-155.

Jamison, Stephanie W. \& Joel P. Brereton. 1987. The Rigveda. Oxford: Oxford University Press. 
Kiparsky, Paul. 1982. The lexical phonology of Vedic accent. Ms. [partially published as Kiparsky, Paul. 1984. A Compositional Approach to Vedic Word Accent. In S.D. Joshi (ed.) Amradhārā. Delhi: Ajanta Publications.].

Kiparsky, Paul. 2006. The amphichronic program vs. evolutionary phonology. Theoretical Linguistics 32(2). 217-236.

Kiparsky, Paul. 2010a. Compositional vs. paradigmatic approaches to accent and ablaut. In Stephanie W. Jamison, H. Craig Melchert \& Bert Vine (eds.), Proceedings of the 21st annual UCLA Indo-European linguistics conference, Bremen: Hempen.

Kiparsky, Paul. 2010b. Dvandvas, blocking and the associative: The bumpy ride from phrase to word. Language 86(2). 301-331.

Lightner, Theodore. 1965. Segmental phonology of modern standard Russian: MIT dissertation. MacDonnell, Anthony A. 1916. A Vedic grammar for students: Motilal Banarsidass.

Mohanan, K. P. 1982. Lexical phonology: MIT dissertation.

Monier-Williams, Monier. 1857. A practical grammar of the Sanskrit language. Oxford: Oxford University Press.

Moskal, Beata. 2015. Limits on allomorphy: A case study in nominal suppletion. Linguistic Inquiry 46(2). 363-376.

Orgun, Orhan. 1996. Sign-based morphology and phonology with special attention to Optimality Theory: UC Berkeley dissertation.

Pater, Joe. 2000. Non-uniformity in English secondary stress: the role of ranked and lexically specific constraints Phonology 17(2). 237-274.

Perry, J. Joseph. 2016. Tone and prosodic constituency in Gyalsumdo: University of Cambridge dissertation.

Scheer, Tobias. 2016. Melody-free syntax and phonologically conditioned allomorphy. Morphology 26(3-4). 341-378.

Svenonius, Peter. 2004. On the edge. In David Adger, Cécile de Cat \& George Tsoulas (eds.), Peripheries: Syntactic edges and their effects, Dordrecht: Kluwer.

Trommer, Jochen. 2011. Phonological aspects of Western Nilotic mutation morphology. University of Leipzig Habilitation Thesis.

Whitney, William Dwight. 1879. A Sanskrit grammar. Gotha: Breitkopf \& Hartel.

Zimermann, Eva. 2016. The power of a single representation: Morphological tone and allomorphy. Morphology 26(3-4). 269-294. 